\title{
Generación de Biogás a través de Biodigestores Anaoerbios
}

\section{Generation of Biogas through Anaerobic Biodigesters}

\author{
SAAVEDRA-RIVERO, Érica*†, PREZA-MEDINA, Sergio Roberto, HERNÁNDEZ-CHACÓN, \\ Sandra y CEBOLLÓN-MEZA, Ángela
}

Universidad Tecnológica de Cancún

ID $1^{\text {er }}$ Autor: Érica, Saavedra-Rivero / ORC ID: 0000-0002-3094-063X, CVU CONACYT ID: 900083

ID 1er Coautor: Sergio Roberto, Preza-Medina / ORC ID: 0000-0001-5010-0585, CVU CONACYT ID: 505691

ID $2^{\text {do }}$ Coautor: Sandra, Hernández-Chacón / ORC ID: 0000-0002-0845-8791, CVU CONACYT ID: 742521

ID $3^{\text {er }}$ Coautor: Ángela, Cebollón-Meza / ORC ID: 0000-0002-2588-061X, CVU CONACYT ID: 747569

DOI: $10.35429 / J B E B .2019 .8 .3 .8 .13$

Recibido 12 de Marzo, 2019; Aceptado 30 Junio, 2019

\section{Resumen}

El objetivo general de este proyecto fue Medir el biogás producido por digestión anaerobia a partir de dos prototipos de biodigestores, suministrados con desechos orgánicos y estiércol de cerdo, en la Universidad Tecnológica de Cancún, para ver qué tipo de desecho es más óptimo en producción de biogás. Para la medición del biogás, primero se construyeron los dos biodigestores y en cada uno se instaló un manómetro para poder medir la presión de gas generado en cada contenedor, de igual manera se instalaron cámaras de bicicletas para almacenar el biogás obtenido y observar qué desecho produce más. Se observó que el biodigestor con estiércol de cerdo proporcionó 11.3 psi y el biodigestor cargado con desechos orgánicos produjo 8.5 psi de biogás. Por lo tanto, se aprecia que el estiércol de cerdo tiene un proceso más rápido en la generación de biogás, que los otros desechos, sin embargo ambos son recomendables para la generación de biogás.

Biodigestor, Biogás, Desechos orgánicos

\begin{abstract}
The general objective of this project was to measure the biogas produced by anaerobic digestion from two prototypes of biodigesters, supplied with organic waste and pig manure, at the Technological University of Cancun, to see what type of waste is most optimal in production of biogas. For the measurement of biogas, first the two biodigesters were built and in each one a pressure gauge was installed to measure the gas pressure generated in each container, in the same way bicycle chambers were installed to store the biogas obtained and observe what waste it produces plus. It was observed that the biodigester with pig manure provided 11.3 psi and the biodigester loaded with organic waste produced $8.5 \mathrm{psi}$ of biogas. Therefore, it is appreciated that pig manure has a faster process in the generation of biogas, than other waste, however both are recommended for the generation of biogas.
\end{abstract}

Biodigester, Biogas, Organic waste

Citación: SAAVEDRA-RIVERO, Érica, PREZA-MEDINA, Sergio Roberto, HERNÁNDEZ-CHACÓN, Sandra y CEBOLLÓN-MEZA, Ángela. Generación de Biogás a través de Biodigestores Anaoerbios. Revista de Ingeniería Biomédica y Biotecnología. 2019. 3-8: 8-13

\footnotetext{
* Correspondencia del autor (Correo electrónico: esaavedra@ utcancun.edu.mx)

$\uparrow$ Investigador contribuyendo como primer autor
} 


\section{Introducción}

El efecto invernadero que se ha registrado en los últimos años a nivel mundial representa un grave problema al planeta. Sin embargo, algunos países de primer mundo inician con métodos limpios en generación de energía, para minimizar dicho impacto. En México se ha iniciado con métodos eólicos y solares principalmente para colaborar al impacto ambiental.

En el sur del país se cuentan con mantos acuíferos que han sido dañados por filtración de lixiviados de proyectos mal elaborados de los vertederos municipales. Asimismo, los desechos orgánicos son una fuente importante para la generación butano, entre otros gases, los cuales contaminan el aire, tierra y los mantos acuíferos por la filtración de sus lixiviados.

Con el objetivo de minimizar el impacto al medio ambiente se construyeron dos prototipos de biodigestores anaerobios con la finalidad de registrar variables (peso, temperatura, presión) para cuantificar el biogás generado por cada uno de los diferentes tipos de materias orgánicas suministrados (desechos orgánicos obtenidos de cocinas y estiércol de cerdo).

Se pretende hacer el proceso de digestión por medio de biodigestores anaerobios para la captación del biogás, por la hermeticidad de los mismos. El proyecto impactará en el medio ambiente y directamente en la Universidad Tecnológica de Cancún (UTC) ya que el biogás se podrá usar en parrillas de las cocinas de la misma universidad y por ende se obtendrá un ahorro en el uso de gas butano.

Los resultados de éste proyecto nos ayudaron a conocer la cantidad de biogás que se generan de diferentes tipos de residuos generados en la UTC para ayudar al medio ambiente y determinar el ahorro energético que se obtendría con éste método de fuentes energéticas alternativas.

\section{Justificación}

En la ciudad de Cancún existen 925 restaurantes aproximadamente en los cuales se generan gran cantidad de desechos orgánicos.
Por esta razón se consideró el uso del biogás como fuente de energía, reciclando los desechos orgánicos y produciendo biogás por medio de un procedimiento llamado digestión anaerobia en el cual los desechos necesitan estar sometido a temperaturas elevadas, aprovechando las condiciones climáticas naturales del estado de Quintana Roo.

\section{Problema}

En la UTC contribuye a la separación de residuos orgánicos e inorgánicos, y se cuantifican las cantidades generadas por edificio, sin embargo, el departamento de colecta de basura del municipio no cuenta con un programa para la separación de residuos y todo se arroja al vertedero municipal los cuales contaminan el subsuelo y por ende los mantos acuíferos. Para contribuir y minimizar el impacto ambiental se planea realizar un prototipo de biodigestor anaerobio para el aprovechamiento de los residuos orgánicos para la generación de biogás y de esta manera minimizar el impacto ambiental a los mantos acuíferos y reduciría el consumo de gas LP y por ende menor consumo de energía fósil.

\section{Objetivos}

\section{Objetivo general}

Producir biogás a través de la digestión anaerobia con dos prototipos de biodigestores suministrados con desechos orgánicos y estiércol de cerdo, para ver qué tipo de desecho es más óptimo en producción de biogás.

\section{Objetivos específicos}

Obtener biogás a partir de la construcción de dos biodigestores anaerobios.

Comparar la cantidad de biogás generado en los distintos biodigestores anaerobios, para ver qué tipo de desecho es más óptimo la producción de biogás.

\section{Preguntas de investigación}

¿Cuánto biogás se obtuvo con los dos prototipos?

¿Qué tipo de desecho orgánico es mejor para la producción de biogás? 


\section{Marco Teórico}

\section{Digestión anaerobia}

Con la constante subida de los precios de los combustibles fósiles, unido a la crisis medioambiental que se genera, se vuelve a valorar la utilidad de los desechos orgánicos y su aprovechamiento para obtener combustibles de ellos. [1]

La digestión anaerobia es un proceso idóneo para llevar a cabo el tratamiento de desechos residuales, pues esto permite el aprovechamiento energético del metano que se produce mediante este proceso (gas con un potencial de calentamiento global 25 veces mayor que el $\mathrm{CO}_{2}$ ), lo que supone una doble ventaja ambiental, por un lado reduce las emisiones de $\mathrm{CO}_{2}$ equivalente a la atmósfera, la obtención de un biofertilizante para el tratamiento de la fertilidad de los suelos, y por el otro, permite la obtención de energía a partir de una fuerte renovable. [2]

De esta manera empieza a entenderse así lo poco sensato que resulta importar o extraer combustibles fósiles de zonas remotas para obtener una energía la cual puede conseguirse en buena medida de los materiales que desechamos habitualmente. [3] La población mundial supera en la actualidad los 5000 millones de habitantes y la producción de residuos sólidos urbanos de cada uno de los habitantes de la Tierra oscila ampliamente según el país, entre los valores de 0,4 y $1,2 \mathrm{~kg} / \mathrm{hab}$ y día. [4]

México es uno de los principales generadores de Metano $\left(\mathrm{CH}_{4}\right)$ derivado de rellenos sanitarios (USEPA, 2005; Johari et al., 2012) y RSU (Rawat y Ramanathan, 2011), localizado dentro de los primeros diez lugares a nivel mundial. Esta problemática, podría convertirse en algo favorable, si a partir de los residuos orgánicos (excretas de ganado y RSU), se produjera biogás para la generación de energía eléctrica en diferentes regiones del país. [5]

La mayor parte de estos residuos son depositados en vertederos incontrolados. Sólo un pequeño porcentaje de los residuos termina en un vertedero controlado, es incinerado o es reintroducido en el ciclo productivo, vía reutilización, reciclaje o compostaje.
Aún en los países occidentales el vertido es la solución más extendida para el tratamiento de los residuos sólidos urbanos. En España, Grecia y Portugal todavía se vierten de forma incontrolada gran parte de los Residuos sólidos urbanos. La Comisión Europea, en la última Propuesta de Directiva sobre vertido de residuos (5 de marzo de 1997), sitúa el vertido muy por detrás de las estrategias de reducción, reciclaje y valorización de los residuos. La propuesta pretende suprimir a medio plazo el vertido de residuos biodegradables, con objeto de reducir las emisiones de lixiviados y de metano. [4]

La producción de biogás es un proceso que ocurre en forma espontánea, en entorno anaerobio, es decir que carece de oxígeno, dicho proceso lo realizan los microorganismos como parte del ciclo biológico de la materia orgánica, el cual involucra la fermentación o digestión de materiales orgánicos para obtener el biogás. [6]

\section{Uso del biogás}

El uso de digestión anaeróbica para extraer metano de desechos de animales y otros medios como residuos del procesamiento de residuos de animales, produce muchos beneficios; reduce gases invernaderos, reduce el uso de combustibles fósiles, reduce la cantidad de materia orgánica en los rellenos sanitarios. Adicionalmente la producción de biogás es una fuente potencial de ingresos económicos para los agricultores. [6] M. Ríos y M. Kaltschmitt sugieren que México tiene un potencial considerable para usar biogás de desechos orgánicos como una fuente renovable para generar electricidad. Los resultados de su investigación muestran un potencial teórico promedio de $167.9 \mathrm{TWh} / \mathrm{año}$, un potencial técnico promedio de $10.2 \mathrm{TWh} /$ año y un potencial económico promedio de $6.4 \mathrm{TWh} /$ año. [10]

\section{Parámetros de funcionamiento}

\section{Tiempo de Retención Hidráulico (TRH):}

Es el tiempo de resistencia que debe permanecer el sustrato en el interior del reactor, se define en la siguiente ecuación:

THR (días) $=V \_R / V \cdot\left[\mathrm{m}^{\wedge} 3\right] /\left[\mathrm{m}^{\wedge} 3 /\right.$ día $]$

$\mathrm{VR}=$ Volumen útil del reactor.

$\mathrm{V}=$ Volumen del sustrato por día. 
Por lo tanto para los reactores con la mezcla, la mayor parte de la digestión se produce en los primeros 20 días.

Etapas del crecimiento bacteriológico:

Etapa de arranque: en ésta etapa se puede acortar recirculando parte de la biomasa extraída del digesto.

Etapa de estabilización: Es la etapa donde mayor de cantidad de metano se produce.

Etapa de declive: en ésta etapa se produce el descenso asintótico en la población bacteriana hasta un valor máximo dependiendo del sustrato.

\section{Velocidad de carga orgánica (VCO)}

Mide la cantidad de materia orgánica biodegradable que es introducida en el digestor al día $(V)$. El porcentaje de materia orgánica contenida en el sustrato se estima mediante el parámetro de Solidos Volátiles (SV).

La VCO se representa mediante la ecuación:

$\mathrm{VCO}=\mathrm{SV} / \mathrm{V}^{\bullet} \mathrm{kg} / \mathrm{m}^{\wedge} 3$

\section{Metodología}

Para el desarrollo del proyecto se programaron tres actividades, las cuales fueron calcular el tiempo de retención de los desechos orgánicos y estiércol de cerdo, medir del biogás obtenido y comparar los resultados. La primera actividad consistió en dejar los biodigestores con sus respectivos desechos en su proceso de descomposición de manera hermética, por lo que se colocaron en un lugar donde el sol les diera directamente, para acelerar el proceso de descomposición y determinar el tiempo necesario que debía estar en retención. La retención, como ya se mencionó, es el periodo de tiempo que permanece la materia orgánica dentro del sistema para alcanzar la degradación. Está directamente relacionado con la temperatura ambiente y en condiciones óptimas del proceso, con una temperatura de $30^{\circ} \mathrm{C}$, el tiempo de retención (Tr) debería ser de 20 días; sin embargo, algunos autores han sugerido para cada ambiente los respectivos tiempos de retención, que comúnmente se presentan en biodigestores [9].
Psicrofílico: Donde la temperatura nunca excede los $25^{\circ} \mathrm{C}$. La actividad bacteriana es baja y el tiempo de digestión puede alcanzar los cien días.

Mesófilo: La temperatura va desde los veinticinco hasta los $45{ }^{\circ} \mathrm{C}$. La actividad bacteriana es media y el tiempo de digestión está comprendido entra los veinte y los sesenta días.

Termófilo: El rango de temperatura va desde los 45 hasta los $80{ }^{\circ} \mathrm{C}$. La actividad bacteriana es alta y el tiempo de digestión se encuentra entre los 10 y los 15. A estas temperaturas se eliminan parte de los microorganismos patógenos, pero se corre el riesgo de que el proceso se vuelva inestable.

El tiempo de retención hidráulico es el tiempo de resistencia que debe permanecer el sustrato en el interior del reactor, se definió con la siguiente ecuación [7]:

$T H R($ días $)=\frac{V_{R}}{\dot{V}} \frac{\left[m^{3}\right]}{\left[m^{3} / d^{\prime} a\right]}$

$\mathrm{VR}=$ Volumen útil del reactor.

$\dot{V}=$ Volumen del sustrato por día.

Tanto para los reactores de mezcla perfecta como para los de flujo pistón, la mayor parte de la digestión de la fracción orgánica de los RSU se produce en los primeros 20 días.

$60 \mathrm{lts}=0.06 \mathrm{~m}^{3}$

4 lts $=0.004 \mathrm{~m}^{3}$

$15($ días $)=\frac{0.06 m^{3}}{\left[0.004 m^{3} / 1 \text { dia }\right]}$

Se llenó una primera vez con cuatro litros de agua y cuatro $\mathrm{kg}$ de desechos, lo cual nos dio un aproximado de tiempo de retención de 15 días. El tiempo de retención es mínimo debido a que se realizó a una escala pequeña. Sin embargo, el biogás producido se midió en tres momentos, el primero a los 20 días, el segundo a los 25 días y el tercero a los 28 días. Para continuar con la segunda actividad, se realizó la medición del biogás producido en el biodigestor cargado con desechos orgánicos y con el biodigestor cargador con estiércol de cerdo. Para realizar este tipo de medición se instaló un manómetro en cada biodigestor, para poder medir la presión de gas generado en cada contenedor, de igual manera se instalaron cámaras de bicicletas para almacenar el biogás obtenido y observar que desecho produce más. 
Para la determinación del desecho orgánico con la mejor producción de biogás, se consideraron las variables de las tablas 1 y 2 .

Tiempo de retención 20 días

\begin{tabular}{lll} 
& Reactor 1 & Reactor 2 \\
& $\begin{array}{l}\text { (Desechos } \\
\text { orgánicos) }\end{array}$ & $\begin{array}{l}\text { (estiércol de } \\
\text { cerdo) }\end{array}$ \\
\hline Temperatura & $28.5^{\circ} \mathrm{C}$ & $28.5^{\circ} \mathrm{C}$ \\
\hline $\mathrm{Ph}$ & 6.7 & 7.9
\end{tabular}

Presión $\quad 7.1 \mathrm{psi}$ psi

Tabla 1

Tiempo de retención 25 días

\begin{tabular}{lll}
\hline & $\begin{array}{l}\text { Reactor 1 } \\
\text { (Desechos } \\
\text { orgánicos) }\end{array}$ & $\begin{array}{l}\text { Reactor 2 } \\
\text { (estiércol de } \\
\text { cerdo) }\end{array}$ \\
\hline Temperatura & $29^{\circ} \mathrm{C}$ & $29{ }^{\circ} \mathrm{C}$ \\
\hline $\mathrm{Ph}$ & 6.7 & 7.9 \\
\hline Presión & $8.0 \mathrm{psi}$ & $10.1 \mathrm{psi}$
\end{tabular}

Tabla 2

\section{Resultados}

Como resultado del objetivo general el biogás producido por los desechos orgánicos y estiércol de cerdo que se comparó (ver tabla 3), se observó que el estiércol de cerdo produjo mayor cantidad de biogás. Los dos contenedores estuvieron expuestos a las mismas condiciones climatológicas, y fueron llenados con la misma cantidad de $\mathrm{kg}$ de desechos y litros de agua. El biogás resultante se almacenó en las cámaras de bicicletas que se instalaron en los contenedores. Se observó que el biodigestor con estiércol de cerdo proporciono 11.3 psi y el biodigestor cargado con desechos orgánicos produjo $8.5 \mathrm{psi}$ de biogás la cual no llenó la cámara de bicicleta.

\begin{tabular}{|c|c|c|}
\hline $\begin{array}{l}\text { Variable } \\
\text { medida. }\end{array}$ & $\begin{array}{l}\text { Biodigestor } \\
\text { cargado con } \\
\text { desechos } \\
\text { orgánicos }\end{array}$ & $\begin{array}{c}\text { Biodigestor } \\
\text { cargado con } \\
\text { estiércol de cerdo. }\end{array}$ \\
\hline $\begin{array}{l}\mathrm{Ph} \text { del } \\
\text { material. }\end{array}$ & 6.7 & 7.9 \\
\hline $\begin{array}{l}\text { Presión } \\
\text { alcanzada } \\
\text { (psi). }\end{array}$ & $8.5 \mathrm{psi}$ & $11.3 \mathrm{psi}$ \\
\hline
\end{tabular}

Tabla 3 Comparación final de mediciones a los 28 días

En la siguiente gráfica se observan las mediciones obtenidas a partir de los 20 días hasta $\operatorname{los} 28$.

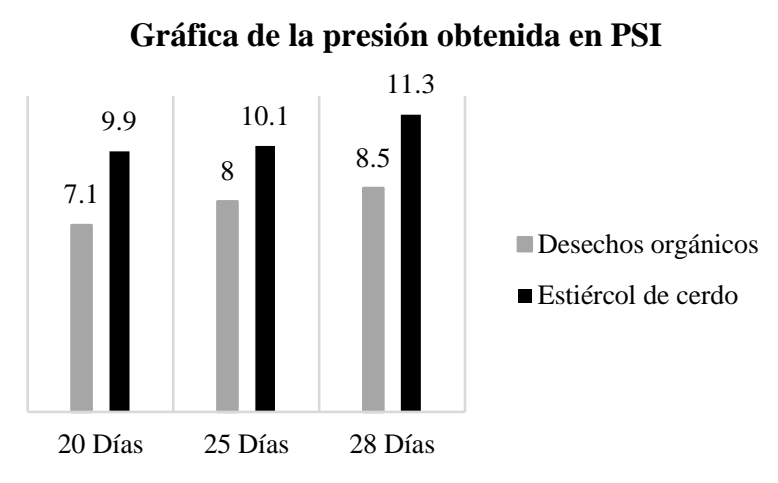

\section{Conclusión}

En la actualidad el cambio climático afecta a todas las regiones del mundo y como consecuencia, existen más sequías, olas de calor, incendios forestales y ha repercutido en la salud de los seres humanos, hoy en día las energías renovables se utilizan más en pro al medio ambiente. El biogás es un combustible confiable que se produce por medio de desechos orgánicos [8].

En la Universidad Tecnológica de Cancún se puede generar biogás a partir de los desechos orgánicos colectados, el cual será capaz de satisfacer la demanda de una de las cocinas de gastronomía y reducirá costos de combustible. Cabe mencionar que es un sistema idóneo para la eliminación de residuos, y es importante seguir sensibilizando a la comunidad universitaria, dando a conocer los beneficios económicos y ambientales, para que a su vez sigan separando residuos, y así transformarlos en biogás. La eficiencia de ésta tecnología colabora a la resolución de materia orgánica expuesta al medio ambiente, y ayuda al sector energético. Es evidente que se generará un costo, sin embargo los beneficios también son grandes, y por ende se justifica. 
Es importante aprovechar experiencias de otros países (Alemania, Italia, china, Reino Unido, Finlandia, Holanda, Francia, etc), y que han seguido avanzando en esta tecnología.

\section{Referencias}

[1] A. R. y. J. E. T. A. Andrade, «Estimación de biogás de relleno sanitario, caso de estudio:,» Entre Ciencia e Ingeniería, vol. 12, nº 23 , pp. 4047, 2018.

[2] A. M. C. E. J. A. José Alberto Díaz Iglesia1, «Metodología para obtención de biogás a partir de residu

os de cosechas del arroz,» AVANCES, vol. 18, $\mathrm{n}^{\circ}$ 4, pp. 325-333, 2016.

[3] E. A. R. Aguilera, «Producción de biogas a partir de Biomasa,» Medio ambiente, tecnología y desarrollo humano., vol. $17, \mathrm{n}^{\circ} 5$, pp. 11-22, 2016.

[4] J. F. R. M. Alejandro W. Padilla Sevillano, «Producción de Biogás y compost a partir de Residuos Orgánicos recolectados del Complejo Arqueológico Huaca de la Luna,» Ciencia y Tecnología, vol. 12, nº 1, pp. 29-43, 2015.

[5] E.-J. M.-V. C.-J. M.-A. X.-S. A. VeraRomero Iván, «Biogás como una fuente alternativa de energía primaria para el Estado de Jalisco, México,» IngenIería InvestIgacIón y tecnología, vol. 18, no 3, pp. 307-320, 2017.

[6] J. J. J.-V. V. M.-C. ,. J. Q.-G. ,. L. A.-C. Miguel A. Osejos-Merino, «Producción de biogás con estiércol de cerdo a partir de un biodigestor en la Granja EMAVIMA Jipijapa Ecuado,» Dominio de las Ciencias, vol. $4, \mathrm{n}^{\circ} 1$, pp. 709-733, 2018.

[7] F. J. A. T. M. A. T. C. B. P. F. Lorena Gabriela Berrelleza Robles, «GENERACIÓN DE BIOGÁS A PARTIR DE RESIDUOS ORGÁNICOS,» El saber de mis hijos hara mi grandeza, vol. 10, n 20 , pp. 5-13, 2016.

[8] J. R. L. C. J. A. S. O. Anahí Karina Tapia Gómez, «KUXULKAB,» Tierra viva o naturaleza en voz de Chontal, vol. 22, $\mathrm{n}^{\circ} 14$, pp. 5-12, 2016.
[9] M. A. B.-L. ,. J. M. B.-L. David Leonardo Parra-Ortiz, «Biomasa residual pecuaria: revisión sobre la digestión anaerobia,» Revista UIS Ingenierías, vol. $18, n^{\circ} 1$, pp. 149160, 2018.

[10] J. O.-G. O. H.-G. V. y. M.-G. D. ESPINAL-ARELLANO, «Potencial de generación de biogás de un rancho ganadero en la comunidad de San Bartolo Cuautlalpan,» Revista de Sistemas Experimentales, vol. 3, $\mathrm{n}^{\circ}$ 8, pp. 36-52, 2016. 